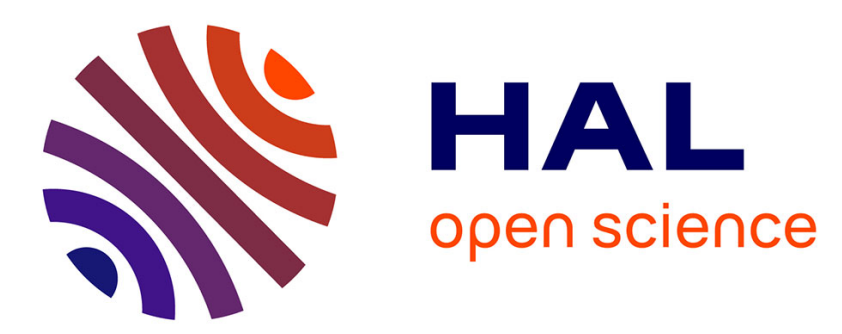

\title{
Asymmetric Effects of Interest Rate Changes: The Role of the Consumption-Wealth Channel
}

\author{
Garry Macdonald, Andrew Mullineux, Rudra Sensarma
}

\section{To cite this version:}

Garry Macdonald, Andrew Mullineux, Rudra Sensarma. Asymmetric Effects of Interest Rate Changes: The Role of the Consumption-Wealth Channel. Applied Economics, 2009, pp.1. 10.1080/00036840902950572 . hal-00582261

\section{HAL Id: hal-00582261 https://hal.science/hal-00582261}

Submitted on 1 Apr 2011

HAL is a multi-disciplinary open access archive for the deposit and dissemination of scientific research documents, whether they are published or not. The documents may come from teaching and research institutions in France or abroad, or from public or private research centers.
L'archive ouverte pluridisciplinaire HAL, est destinée au dépôt et à la diffusion de documents scientifiques de niveau recherche, publiés ou non, émanant des établissements d'enseignement et de recherche français ou étrangers, des laboratoires publics ou privés. 


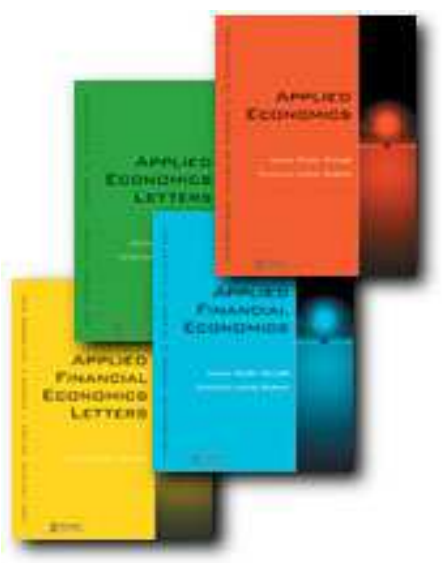

\section{Asymmetric Effects of Interest Rate Changes: The Role of the Consumption-Wealth Channel}

\begin{tabular}{|r|l|}
\hline Journal: & Applied Economics \\
\hline Manuscript ID: & APE-07-0555.R1 \\
\hline Journal Selection: & Applied Economics \\
\hline Date Submitted by the \\
Author: & 19-Nov-2008 \\
\hline Complete List of Authors: & $\begin{array}{l}\text { MacDonald, Garry; Curtin University, Economics and Finance } \\
\text { Mullineux, Andrew; University of Birmingham, Accounting and } \\
\text { Finance } \\
\text { Sensarma, Rudra; University of Hertfordshire, Business School }\end{array}$ \\
\hline Keywords: & $\begin{array}{l}\text { E52 - Monetary Policy (Targets, Instruments, and Effects) }<\text { E5 - } \\
\text { Monetary Policy, Central Banking, and the Supply of Money and } \\
\text { Credit < E - Macroeconomics and Monetary Economics } \\
\text { channel }\end{array}$ \\
\hline & \\
\hline
\end{tabular}

\section{S) ScholaroNE \\ Manuscript Central}


ASYMMETRIC EFFECTS OF INTEREST RATE CHANGES: THE ROLE OF THE CONSUMPTION-WEALTH CHANNEL

\author{
Garry MacDonald \\ Associate Professor \\ School of Economics and Finance, Curtin Business School, Perth WA 6845, Australia \\ Email: Garry.MacDonald@cbs.curtin.edu.au \\ Andy Mullineux (Corresponding Author) \\ Professor of Global Finance \\ Birmingham Business School, University of Birmingham, Birmingham B15 2TT, UK \\ Email: a.w.mullineux@bham.ac.uk \\ Rudra Sensarma \\ Senior Lecturer \\ Business School, University of Hertfordshire, Hatfield Herts AL10 9AB, UK \\ Email: rsensarma@gmail.com
}

\begin{abstract}
This paper examines the role of the consumption-wealth channel in explaining asymmetric effects of monetary policy changes. Towards this end, we draw upon available literature on the consumption function and behavioural finance to construct a framework for asymmetric effects of monetary policy caused by the impact of wealth changes on aggregate consumption. We then employ data from the UK to examine the validity of the proposed framework. In the context of a liberalized economy with easy access to consumer credit, wealth reduction due to monetary tightening is expected to have weaker impact on spending than increase in wealth. Our results validate the above hypothesis.
\end{abstract}




\section{Asymmetric Effects of Interest Rate Changes: The Role of the Consumption-Wealth Channel}

\section{Introduction}

There is overwhelming evidence to show that monetary policy exerts significant influence on national output through aggregate demand (Bernanke and Blinder, 1992; Christiano et al., 1996). It is also well known in the theoretical literature that the transmission channels of monetary policy are the credit channel, the interest rate channel, the exchange rate channel and the wealth channel. While the first three channels have been extensively examined, empirical research on the wealth channel has remained restricted to the impact of monetary policy on asset prices. What has not received adequate attention is the entire pass-through of monetary policy changes on consumption expenditure through movement in asset prices and household wealth. On the other hand, the theoretical roots of this consumption-wealth channel can be traced back to as early as works by Modigliani (1963) and Ando and Modigliani (1963). Their life-cycle theory of consumption emphasizes the role played by household wealth in planning for life-time consumption. However this theory and subsequent work on the permanent income hypothesis by Friedman (1957) postulate that households are consumption smoothers and plan for an entire life-time consumption pattern. In such a framework, there can be little role of monetary policy in so far as the impact of interest rate shocks would be muted. This would be more so in developed financial systems where easy access to consumer credit would allow households to smoothen their consumption patterns. 
The ease of access to consumer credit may However, recent work has raised concerns about the strong co-movement exhibited by asset prices and consumption (Dynan and Maki, 2001; Lustig and Van Nieuwerburgh, 2005). Such correlation has strong bearings on the conduct of monetary policy to the extent that monetary policy shocks impact asset prices and thereby household wealth. While this sensitivity of consumption to wealth changes does not appear to be consistent with the traditional views on consumption, policy makers have been taking increasing cognizance of the importance of this phenomenon (Borio et al., 2003). The explanation for this apparent puzzle could lie in the easy access to mortgage equity withdrawals, mortgage re-finance and cheap trading in shares that are possible in developed financial systems. Such easy access to funds whenever required means that any changes in asset prices can be readily translated into liquidity which can then be used for spending on durable or non-durable goods and services. Thus, developed countries could have a section of such 'impatient' consumers whose transitory component of total consumption is significant and easily affected by asset price changes. This would imply the existence of a consumption-wealth channel of monetary policy transmission in such economies. While the wealth channel could fuel a boom in consumption, it has also been recognized in the literature that reserve requirements and capital regulations on banks have led to pro-cyclicality in lending (Bliss and Kaufman, 2002) and recent developments in the financial system could have amplified swings in economic activity (Borio et al., 2001). However our focus is on a period which was characterized by a regime of falling interest rates and relative stability in economic activity. It is during this period that we seek to investigate the importance of wealth factors in the monetary policy transmission process. 
A recent strand of the monetary policy literature examines asymmetric effects of policy changes. However, as Florio (2004) points out, most of the work related to asymmetric effects of monetary policy has been empirical in nature and the theoretical underpinnings of this phenomenon have been less discussed. In a survey of the asymmetry literature, Florio (2004) documents the following as available explanations: expectations (about future business outlook or inflation), asymmetric price adjustment and credit market imperfections. In this context, the purpose of the present work is to examine the role of the consumption-wealth channel as a possible factor in explaining asymmetric effects of monetary policy changes. Towards this end, we draw upon available literature on the consumption function and behavioural finance to construct a framework of asymmetric effects of monetary policy caused by the consumption-wealth channel. We then employ data from the UK to examine the validity of the proposed framework. In the context of a liberalized economy with easy access to consumer credit, wealth reduction due to monetary tightening is expected to have weaker impact on spending than increase in wealth. Our results provide empirical support for this argument.

\section{Consumption-wealth channel and asymmetry}

The consumption-wealth channel of monetary policy traces the impact of interest rate changes on aggregate consumption through change in market value of assets. Modigliani (1971) is one of the earliest works to demonstrate that consumer spending plays a critical role in transmitting the effects of monetary policy changes to the real economy through the wealth channel. In reality, the changes in wealth could arise due to changes in value 
of either financial assets or housing. Consequently, consumption may be affected by housing wealth and housing wealth holdings directly rather than indirectly, say through company pension funds. Interest rate shocks can affect consumption through the wealth channel in two ways. First, lower interest rates would lead to higher house prices which increases the asset wealth of existing house owners ${ }^{1}$. Such households can then convert these capital gains from their property into liquid spending power through mortgage equity withdrawal, i.e. extracting equity from the higher value of houses by borrowing more $^{2}$. This enhanced liquidity can then be used for financing consumption of durables or non-durables. Second, lower interest rates can also boost the market value of financial assets (e.g. market price of shares and bonds are sums of future income streams discounted by what is now a lower interest rate). Thus higher financial wealth can also reduce the need to save and hence release liquidity for consumption spending.

However recent empirical research has provided only weak support for the existence of the consumption-wealth channel of monetary policy transmission. Ludvigson et al. (2002) employed US data from 1966 to 2000 to study the monetary policy transmission to consumption. Their results reveal only a weak role for the wealth channel in transmitting the Federal Reserve's monetary policy changes to consumption spending. Siokis (2005) investigated the consumption-wealth channel of monetary policy transmission in the Euro area by examining data from 1977 to 2002. The results indicate that the wealth channel does not play an important role in transmission of interest rate

\footnotetext{
${ }^{1}$ While interest rates affect asset prices through the usual discounted cash flow mechanism, there is also an indirect channel through which interest rates act which is by first impacting household consumption and demand for assets thereby leading to change in asset prices.

${ }^{2}$ For older house owners, equity release is another channel of extracting equity from higher house prices to finance current consumption.
} 
changes to consumption. Both these papers employed the structural vector auto regression (SVAR) methodology to isolate the impact of endogenous wealth changes on consumption. We intend to revisit the issue of consumption-wealth channel of monetary policy transmission by examining data from the UK through a similar SVAR model and then examine asymmetry in the transmission channel through a set of estimations of the consumption function.

Kahneman and Tversky (1979) in their influential work on what has come to be known as behavioural finance offered the concept of prospect theory. According to this theory, individuals loath losses more than they like gains. This is manifested in a utility function that is concave in gains but convex in the region of losses. It is reasonable to expect that such preferences would suggest consumption behaviour of the Duesenberry (1949) type where the consumption function is steeper for increases in wealth but flatter for wealth reductions. This is the well known Ratchet effect in consumption. Following from these rationales, it is reasonable to expect that increase in wealth may lead to higher consumption but a fall in wealth may lead to a smaller reduction in consumption in absolute terms. Consumers may take recourse to past savings or other sources of credit (primarily unsecured, e.g. credit cards) to mitigate the adverse impact of wealth reduction on consumption.

Thus, this argument introduces the possibility of asymmetry in the consumption-wealth channel of monetary transmission. In other words, the pass-through is now as follows. Lower interest rates lead to higher wealth which can be used by households to finance 
higher consumption through equity withdrawals, higher mortgage or increased willingness to spend in general. On the other hand, higher interest rates lead to lower wealth which may not proportionately reduce consumption due to the prospect theory and ratchet effect arguments. In sum, interest rate changes inversely affect asset value which may have asymmetric effects on consumption at least in the short to medium term. Clearly, we are dealing with two issues here. First, does the consumption wealth channel work? Second, can the consumption-wealth channel explain the asymmetric effects of interest rate changes?

Previous studies have explored asymmetries in the response of household consumption to changes in financial and non-financial wealth. Apergis and Miller (2004) found that positive stock market wealth shocks affect consumption more than negative shocks. Disney et al. (2002) found that impact of house prices on consumption in the UK is stronger when house prices are rising rather than falling. However our objective is to examine asymmetries in the impact of monetary policy shocks on aggregate wealth and consumption. In other words, we intend to study the monetary transmission channel through aggregate wealth, its impact on consumption expenditure, and examine the presence of asymmetries therein.

\section{Data and methodology}

The data were downloaded from the website of the Office of National Statistics (www.statistics.gov.uk) where recent time-series data on macroeconomic variables and financial wealth were available. The non-financial wealth series was constructed from 
house prices and private sector dwelling investment data using the methodology outlined by Fernandez-Corugedo et al. (2007). Quarterly data from 1991:Q1 to 2006:Q2 are considered for the following variables: household consumption, income (household's net labour income), financial wealth (household's net worth) and non-financial wealth (gross housing wealth), inflation and interest rate (Bank of England's official base rate). Consumption, income and wealth data are taken as real and de-seasonalized whereas inflation and interest rate are nominal and de-seasonalized. In order to have a preliminary understanding of the data, we plot the variables of interest in terms of their levels, logarithms and growth-rates as relevant (see figure 1).

(Figure 1 about here)

The focus of the empirical work is on potential asymmetry in the consumption-wealth channel, however it seems logical to first question whether the wealth channel is of significance in the transmission mechanism, since if we find that it is not any potential asymmetry of response may be of limited interest to policy makers. To this end this we proceed in two stages. In section 4 we borrow a frequently used SVAR framework to see if there is evidence that the wealth effect does play a role. The SVAR results suggest that the wealth channel is indeed of empirical importance and so we proceed in section 5 to a closer analysis of the impact of wealth changes on consumption in a more focused and traditional time series approach to see if there is evidence of asymmetry. We move away from the SVAR framework for two reasons, firstly the SVAR takes no account of the time series properties of the data and in particular the possibility of cointegrating 
relationships amongst the series considered and secondly, due to the relatively small sample size we find that we are able to focus on a more parsimonious representation of the relationship between consumption and wealth.

\section{The SVAR model}

As a first step we begin by establishing the importance of the wealth channel on consumption and to do this we borrow the macroeconometric framework of Ludvigson et al. (2002) also employed by Siokis (2005). This approach consists of estimating a structural vector autoregression (SVAR) model with five variables, namely: inflation, income, consumption, wealth and the interest rate. This model is employed as a benchmark model to trace the impulse responses of consumption to an interest rate shock. While this impact on consumption includes the transmission of monetary policy through the wealth channel, a counterfactual can be constructed that shuts down the wealth channel. This experiment provides the direct impact of interest rate on consumption through channels other than the wealth channel. Any difference between the two responses can therefore be attributed to the presence of the wealth channel. The SVAR is clearly described in Ludvigson et al. (2002) and we focus here on the key elements. The SVAR is of the AB type (Amisano and Giannini, 1997) and the focus is the restrictions on the A matrix of contemporaneous relationships amongst the variables ${ }^{3}$. Including the wealth channel the A matrix takes the form:

\footnotetext{
${ }^{3}$ The B matrix is assumed to be diagonal and the total number of restrictions is just sufficient to identify the SVAR. 


$$
A=\left[\begin{array}{ccccc}
1 & 0 & 0 & 0 & 0 \\
a_{21} & 1 & 0 & 0 & 0 \\
a_{31} & a_{32} & 1 & a_{34} & 0 \\
a_{41} & a_{42} & 0 & 1 & a_{45} \\
a_{45} & a_{52} & a_{53} & 0 & 1
\end{array}\right]
$$

where the variables are, in order: inflation, income, consumption, wealth and the interest rate $^{4}$.

The restrictions on the A matrix are those suggested in Ludvigson et al. (2002) and are based on the following assumptions: the interest rate responds contemporaneously to consumption and income, but not the other way round; consumption is contemporaneously affected by wealth, but the opposite is not true; and finally, the interest rate does not contemporaneously respond to changes in wealth (see Ludvigson et al., 2002 for further details). The above model is then estimated by the maximum likelihood method (Amisano and Giannini, 1997) and the impulse responses calculated. The counterfactual impulse responses, turning the wealth effect off, can then be calculated by i) setting the element $\mathrm{a}_{34}$ in A equal to zero and ii) setting the coefficients on lagged wealth terms in the consumption equation of the estimated VAR model equal to zero. The impulse responses can then be recalculated with the wealth channel turned

\footnotetext{
${ }^{4}$ The VAR was estimated with a maximum lag of 6 and then the lag length selected on the basis of information criteria, $\mathrm{F}$ tests on lag length reduction and error diagnostics. Results from a VAR with lag length of 5 which showed no evidence of autocorrelation in the errors of the equations of the VAR for either system are reported here. The model was re-estimated using 6 lags and the results were found to be similar. The results shown here used end of quarter wealth but were once again substantially the same using beginning of period wealth (see Ludvigson et al., 2002).
} 
off $^{5}$. The key impulse responses for our purposes are the ones showing how consumption and wealth respond to a shock to in the interest rate and how consumption responds to wealth shocks.

The full set of impulse responses is in the appendix and we focus here on two key results. The first is that shocks to wealth appear to have a positive and significant impact on consumption. This is an encouraging result for our hypothesis since it does suggest that wealth changes have the potential to influence consumption. The second is that consumption responds positively (though the confidence intervals frequently include zero) to a rise in interest rates, this seems somewhat counterintuitive and warrants further investigation. Figure 2 shows the consumption response to an interest rate shock both with the wealth channel and without the wealth channel.

(Figure 2 about here)

As we can see the turning off of the wealth channel leads to consumption falling after an interest rate rise and the impulse response lies outside the confidence interval suggesting that turning off the wealth channel leads to a significant difference. Our interpretation of these results is that a rise in the base rate without the wealth channel does lower consumption, however wealth responds positively to a base rate rise and this can act to raise consumption leading to the somewhat paradoxical result above. This then leaves the

\footnotetext{
${ }^{5}$ The VAR and SVAR were estimated in Jmulti (Lutkepohl and Kratzig 2004) and a gauss program was used to re-compute the impulse responses once the relevant restrictions were imposed on the VAR coefficients and the A matrix. A full set of all of the impulse responses is available from the authors on request.
} 
question as to why wealth rises when the base rate rises. To gain further insights into this response we re-estimated the SVAR using a long term interest rate (the 20-year par yield on British Government Securities) and found that both consumption and wealth now responded negatively to a rise in interest rates (with and without the wealth channel), we then regressed the first difference of the long term rate against lags of the first difference of the short run rate, the results suggested a long run inverse relationship between changes in the base rate and changes in the long run rate $^{6}$. On this basis our interpretation of the impulse responses (which must be taken in the context of the simple SVAR in which they are estimated) is; a rise in the base rate generates an expectation of lower inflation and falling long run interest rates and it is these that lead to the positive wealth effects. These positive wealth effects then support consumption which would otherwise fall (in the absence of the wealth channel) in the face of the base rate rise.

We draw two simple conclusions from these simulations. Firstly, irrespective of which interest rate we use, shocks to wealth have a positive impact on consumption. Secondly, again irrespective of the interest rate used there is evidence that "turning off" the wealth effect impacts on consumption and that the wealth channel is therefore of importance and warranting further investigation. To do this we turn now to a more traditional econometric analysis of the data which allows us to a) consider more parsimonious specifications and b) take into account the time series properties of the data.

\section{Modeling potential asymmetry}

\footnotetext{
${ }^{6}$ A full set of these results is available from the authors on request.
} 
In this section we resort to more standard econometric modeling with the aim of focusing more particularly on the role that wealth changes play in consumption and the potential asymmetry in this relationship. Unit root tests of the 5 variables in the SVAR suggest that inflation is $\mathrm{I}(0)$, whilst all the other variables, including both interest rates, are $\mathrm{I}(1)^{7}$. As a result and because inflation is unlikely to play a significant role in the transmission mechanism itself we begin by focusing on the four variables wealth, income, consumption and the base rate.

We find that cointegration tests for the four variable system $(\mathrm{C}, \mathrm{Y}, \mathrm{W}, \mathrm{r})$ suggest some evidence of a single cointegrating vector, with the trace test significant at 4.85 percent and the maximum eigenvalue test at 10.5 percent. The cointegrating vector $(-1,0.3898$, 0.2908, -0.026) suggests that both income and wealth have positive long run effects on consumption and the interest rate a negative effect ${ }^{8}$. Tests on the loading vector suggest that both wealth and income are weakly exogenous with LR tests of a zero restriction being insignificant with p-values of 0.41 for income and 0.64 for wealth, however both consumption and the base rate reject the restriction with p-values of 0.03 and 0.04 respectively. These results do not necessarily conflict with those from the SVAR, wealth and income do not adjust to the long run equilibrium but the base rate and consumption

\footnotetext{
${ }^{7}$ These are available from the authors on request. As the beginning of the 1990s witnessed a speculative attack on the European Monetary System, we repeated the unit root tests for the period beginning in 1994. However the conclusions remained unchanged.

${ }^{8}$ Information Criteria were used to test the lag order in the VAR, setting a maximum lag of 6 all 4 Information criteria, Akaike, FPE, Hannan_Quinn and Schwarz suggested a lag order of 2 and diagnostics on the $\operatorname{VAR}(2)$ were acceptable. The cointegration tests were carried out allowing for a linear deterministic trend by including a constant in the error correction and the VAR. Tests on the cointegrating vector suggested that $\mathrm{Y}$ was not significant and testing with a 3 variable system $(\mathrm{C}, \mathrm{W}, \mathrm{r})$ suggested that the null of zero cointegrating vectors was rejected at 5.8 percent for the Trace test and 4.1 percent for the maximum eigenvalue test. Once again wealth appeared to be weakly exogenous and the cointegrating vector was $(-1$, $0.381,-0.05)$. However the error correction term from both cointegrating vectors was very similar and all following results did not differ significantly so we report only results from the 4 variable system, all other results are available from the authors on request.
} 
do reflecting the use of monetary policy to control aggregate demand. Ignoring wealth effects the base rate has the expected negative effect on consumption (as it did in the restricted SVAR) and the weak exogeneity of wealth, whilst it suggests that wealth does not participate in the error correction does not preclude wealth dynamics impacting on consumption. This suggests that if, as we do below, we focus on the consumption equation in the VECM it will be important to include the error correction term. The results of estimation of the single equation for $\Delta \mathrm{C}$ are presented below, including 2 lags in all variables. As can be seen the regression equation shows only the error correction term to be significant ${ }^{9}$.

$$
\begin{aligned}
& \Delta C=\underset{(.000)}{0.008}-\underset{(.017)}{0.071} e \mathrm{em}_{t-1}-\underset{(.105)}{0.245 \Delta C_{t-1}}+\underset{(.768)}{0.045 \Delta C_{t-2}} \\
& +\underset{(.140)}{0.048 \Delta W_{t-1}}-\underset{(.0296)}{0.027} \Delta W_{t-2}-\underset{(.043)}{0.023 \Delta Y_{t-1}}-\underset{(.891)}{0.009 \Delta Y_{t-2}}-\underset{(.857)}{0.000} \Delta r_{t-1}+\underset{(.386)}{0.002} \Delta r_{t-2} \\
& \mathrm{R}^{2}=0.254
\end{aligned}
$$

AR 1-4 test: $\quad \mathrm{F}(4,45)=0.82553[0.5159]$

ARCH 1-4 test: $\mathrm{F}(4,41)=1.9428[0.1216]$

Normality test: $\mathrm{Chi}^{2}(2)=4.6255$ [0.0990]

Heteroscedasticity test: $\mathrm{F}(18,30)=2.1133$ [0.0339]*

A model reduction sequence ${ }^{10}$ yielded the following parsimonious representation with now the first lag of consumption being significant but no role for any other variables.

$$
\Delta C=\underset{(.000)}{0.009}-\underset{(.002)}{0.078} e c m_{t-1}-\underset{(.046)}{0.254 \Delta C_{t-1}}
$$

$\mathrm{R}^{2}=0.176$

AR 1-4 test: $\quad \mathrm{F}(4,52)=1.0388[0.3962]$

ARCH 1-4 test: $\mathrm{F}(4,48)=1.2310[0.3103]$

Normality test: $\mathrm{Chi}^{2}(2)=2.5117[0.2848]$

Heteroscedasticity test: $\quad \mathrm{F}(4,51)=1.4526$ [0.2304]

\footnotetext{
${ }^{9} \mathrm{p}$-values in parenthesis below estimated coefficients.

${ }^{10}$ We used the automatic model reduction algorithm in PC-Give (Doornick and Hendry 2007) to carry out all reduction sequences, this has the advantage in this case of ensuring consistency in the model reduction process.
} 
Since our interest is focused on the potential asymmetry of wealth dynamics on consumption behaviour we define $\Delta \mathrm{w}^{+}$and $\Delta \mathrm{w}^{-}$such that we split the dynamics of wealth into periods when the first difference is positive and negative respectively and reestimate equation (1) as (3) below ${ }^{11}$. As can be seen the error correction term is significant and correctly signed at 1 percent, the first lag of consumption at 6 percent and the first lag of positive wealth changes at 8 percent giving us the first intimation of possible importance for non- symmetric effects.

$$
\begin{aligned}
& \Delta C=\underset{(.003)}{0.007}-\underset{(.010)}{0.078} e c m_{t-1}-\underset{(.063)}{0.286} \Delta C_{t-1}+\underset{(.967)}{0.007} \Delta C_{t-2}-\underset{(.723)}{0.026} \Delta W_{t-1}^{-}-\underset{(.194)}{0.094} \Delta W_{t-2}^{-} \\
& +\underset{(.078)}{0.084} \Delta W_{t-1}^{+}+\underset{(.727)}{0.016 \Delta W_{t-2}^{+}}-\underset{(.063)}{0.031} \Delta Y_{t-1}-\underset{(.859)}{0.012 \Delta Y_{t-2}}+\underset{(.926)}{0.000} \Delta r_{t-1}+\underset{(.368)}{0.002} \Delta r_{t-2} \\
& \mathrm{R}^{2}=0.287031
\end{aligned}
$$

ARCH 1-4 test: $\quad F(4,39)=1.4342[0.2410]$

Normality test: $\mathrm{Chi}^{2}(2)=3.2410$ [0.1978]

Heteroscedasticity test: $\quad \mathrm{F}(22,24)=1.1899$ [0.3379]

Once again the model reduction yields a simple parsimonious representation (1991:Q1 to 2006:Q2)

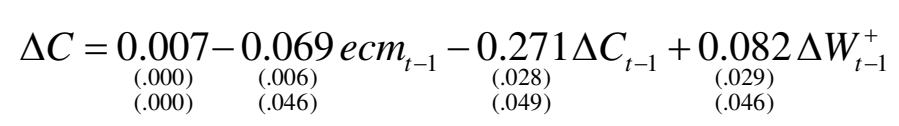

$\mathrm{R}^{2}=0.245232$

AR 1-4 test: $\quad F(4,51)=0.65156[0.6284]$

ARCH 1-4 test: $F(4,47)=2.1933[0.0842]$

Normality test: $\mathrm{Chi}^{2}(2)=2.6379[0.2674]$

Heteroscedasticity test: $\mathrm{F}(6,48)=2.4733[0.0364]^{*}$

\footnotetext{
${ }^{11}$ In our sample, 44 periods recorded positive wealth growth and 17 periods recorded negative wealth growth.
} 
Since this fails the Heteroskedasticity test at $5 \%^{12}$ we also provide, in the second set of parenthesis below the estimated coefficients, the HCSE's p-values. Comparing the two sets of results we can see that when no allowance was made for the potential asymmetry in wealth effects wealth played no role in the consumption equation, once allowance is made there is a clear significant impact of wealth changes when they are positive and this effect is correctly signed in that it suggests, as did the SVAR that a rise in wealth has a positive effect on consumption. Figure 3 shows the "actuals and fitteds" over the sample period both including (top graph) and excluding (bottom graph) the positive wealth dynamics.

(Figure 3 about here)

Whilst it is easy to read too much into these plots they do suggest that the fit of the model is most clearly improved over the middle period of the sample, around 1996 to 2001 . This was the period when the wealth variable was not only rising but also appeared to be above trend ${ }^{13}$. Re-estimation of the simple dynamic model over this sub sample seems to confirm the importance of wealth gains over this period for consumption dynamics with the positive wealth dynamics variable being significant at $2 \%$ and the lagged consumption variable at $6 \%$ whilst the error correction term is now insignificant. One potential interpretation is that over this period (when the base rate showed periods of both

\footnotetext{
${ }^{12}$ This is most likely in part due to the nature of the wealth variable which takes the value zero for part of the sample so the residuals for that part are likely to be "larger" causing the apparent heteroscedasticity - to check this we re-ran the regression including the insignificant $\Delta \mathrm{w}^{-}$variable and found that the heteroskedasticity test was no longer significant at the 5\% level.

${ }^{13}$ Using a simple Hodrick Prescott filter and looking at the above trend periods confirms this as the one period in the sample where wealth was clearly above the fitted trend.
} 
monetary loosening and tightening) the strong wealth gains played a stronger role in bolstering consumption as suggested by the SVAR results.

$\Delta C=\underset{(.001)}{0.009}-\underset{(.376)}{0.059} e c m_{t-1}-\underset{(.060)}{0.354 \Delta C_{t-1}}+\underset{(.019)}{0.101} \Delta W_{t-1}^{+}$

p-values in parenthesis

The estimation sample is: 1996(1) - 2001(4)

$\mathrm{R}^{2}=0.376392$

AR 1-2 test: $\quad \mathrm{F}(2,18)=0.27309[0.7641]$

ARCH 1-2 test: $F(2,16)=1.5778[0.2369]$

Normality test: $\mathrm{Chi}^{2}(2)=0.60650[0.7384]$

Heteroscedasticity test: $\quad \mathrm{F}(6,13)=0.24675[0.9521]$

\section{Concluding remarks}

This paper represents a first attempt at modeling potential asymmetry in the response of consumption to monetary policy via the wealth component of the transmission mechanism. Utilising a popular SVAR representation we find that "turning off" the wealth effect makes a significant difference to the response of consumption to shocks to the Bank of England's official policy instrument the base rate and that positive wealth shocks have a significant positive effect on consumption. These findings are backed up with results from the estimation of a simple model of consumption dynamics which suggests that wealth dynamics do play a significant role in determining consumption but only when they are positive. These results are particularly strong for the period from the mid 1990's to early 2000's when the growth in wealth in the UK was particularly strong. The asymmetry in the consumption-wealth channel suggests that the central bank should take cognizance of the fact that monetary tightening will not reign in consumption growth to the desired extent, especially during periods when wealth growth is strong. This makes 
it important to re-assess monetary policy measures especially during periods of asset price inflation and rising price inflation. Pre-emptive and progressive interest rate increases may be required to dampen asset price increases and contain future inflation. 


\section{References}

1. Amisano, G and Giannini (1997) Topics in Structural VAR Analysis, 2nd edition Springer-Verlag, Berlin.

2. Ando, A. and Modigliani, F. (1963) The life cycle hypothesis of saving: aggregate implications and tests. American Economic Review, 53, 55-84.

3. Apergis, Nicholas and Miller, Stephen M. (2004) Consumption Asymmetry and the Stock Market: Empirical Evidence. Working papers 2004-43, University of Connecticut, Department of Economics.

4. Bernanke, B. and Blinder, A. (1992) The federal funds rate and the channels of monetary transmission. American Economic Review, 82, 901-921.

5. Bliss, R. and Kaufman, G. (2002) Explaining Bank Credit Crunches and Procyclicality, Chicago Fed Letter, No. 179, Federal Reserve Bank of Chicago.

6. Borio, C. E. V., Furfine, C. and Lowe, L. (2001) Procyclicality of the Financial System and Financial Stability: Issues and Policy Options, Papers No. 1, Basel: Bank for International Settlements.

7. Borio, C. E. V., English, W. and Filardo, A. (2003) A Tale of Two Perspectives: Old or New Challenges for Monetary Policy?, Papers No. 127, Basel: Bank for International Settlements.

8. Christiano, L. J., Eichenbaum, M. and Evans, C. (1996) The effects of monetary policy shocks: evidence from the flow of funds. Review of Economics and Statistics, 78(1), 16-34. 
9. Disney, R. F., Henley, A. and Jevons, D. (2002) House price shocks, negative equity and household consumption in the UK in the 1990s. Presented at the $57^{\text {th }}$ European meeting of the Econometric Society, Venice.

10. Doornick, J.A. and Hendry, D. (2007) PC-Give version 12, Timberlake Consultants Ltd, London

11. Dynan, K. E. and Maki, D. M. (2001) Does Stock Market Wealth Matter for Consumption?, Finance and Economics Discussion Series 2001-23, Board of Governors of the Federal Reserve System.

12. Duesenberry, J. S. (1949) Income, saving and the theory of consumer behaviour. Princeton University Press, Princeton.

13. Fernandez-Corugedo, E., Price, S. and Blake, A. (2007) The dynamics of aggregate UK consumers' non-durable expenditure, Economic Modeling, 24(3), 453-469.

14. Florio, A. (2004) The asymmetric effects of monetary policy, Journal of Economic Surveys, 18(3), 409-426.

15. Friedman, M. (1957) A theory of the consumption function. Princeton university press, Princeton.

16. Ludvigson, S., Steindel, C. and Lettau, M. (2002) Monetary policy transmission through the consumption-wealth channel, Economic Policy Review, Federal Reserve Bank of New York, May, 117-133.

17. Lustig, H. N. and Van Nieuwerburgh, S. G. (2005) Housing Collateral, Consumption Insurance, and Risk Premia: An Empirical Perspective, Journal of Finance, 60(3), 1167-1219. 
18. Lutkepohl, H. and Kratzig, M. (eds.) (2004) Applied Time Series Econometrics, Cambridge University Press, Cambridge.

19. Kahneman, D. and Tversky, A. (1979) Prospect theory: an analysis of decision under risk. Econometrica, 47(2), 263-292.

20. Modigliani, F. (1963) The monetary mechanism and its interaction with real phenomena. Review of Economics and Statistics, 45, 79-107.

21. Modigliani, F. (1971) Consumer spending and monetary policy: the linkages. Federal Reserve Bank of Boston Conference Series 5.

22. Siokis, F. M. (2005) Policy transmission and the consumption-wealth channel, Applied Financial Economics Letters, 1(6), 349-353. 
FIGURE 1

Macroeconomic variables, UK, 1991:Q1 to 2006:Q2

Log of consumption

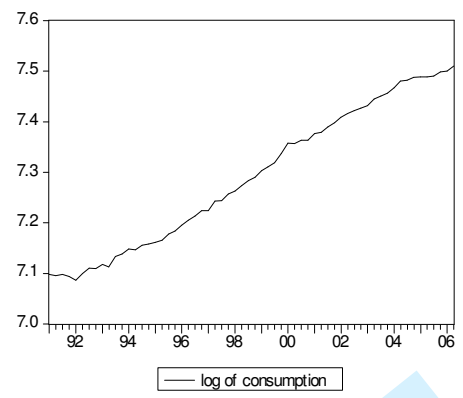

Log of wealth

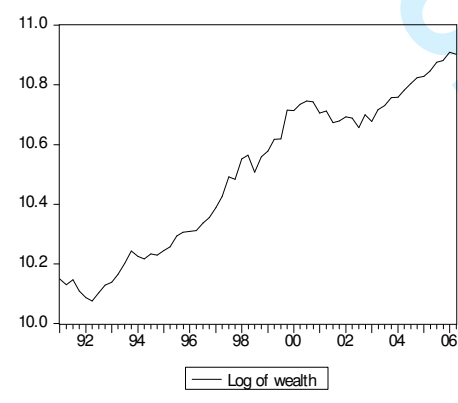

Consumption growth

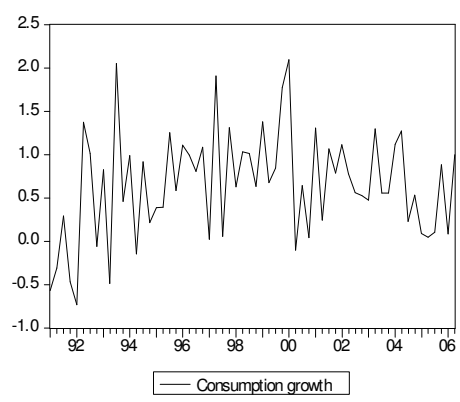

Wealth growth

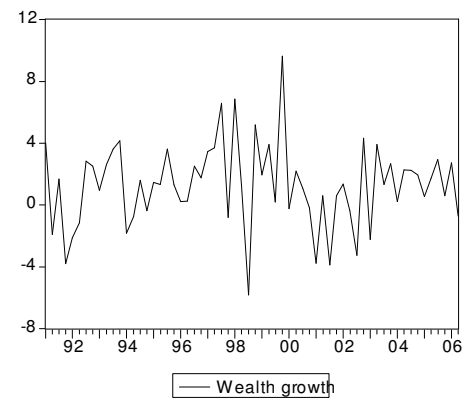

Log of income



Interest rate

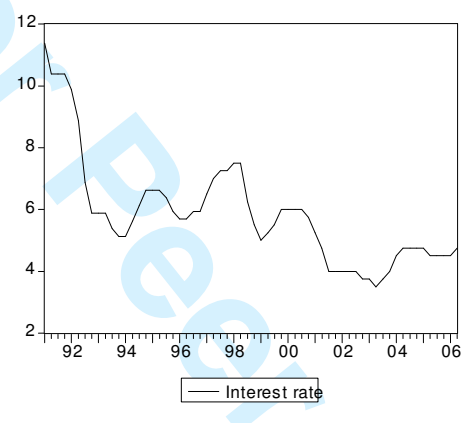

Income growth

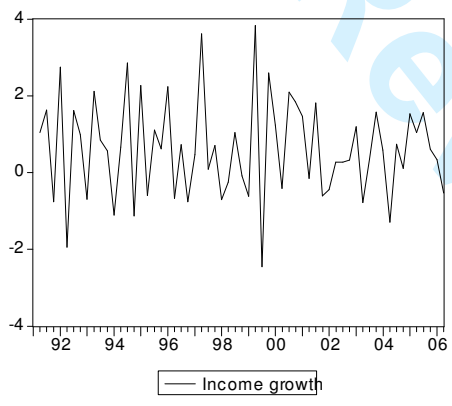

Inflation

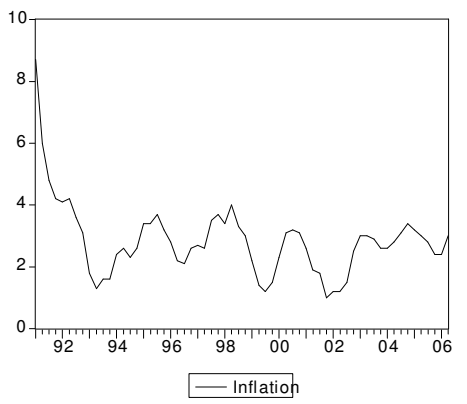

58

59

60

Editorial Office, Dept of Economics, Warwick University, Coventry CV4 7AL, UK 
FIGURE 2

Impulse responses showing response of consumption to a shock to the short term interest rate.

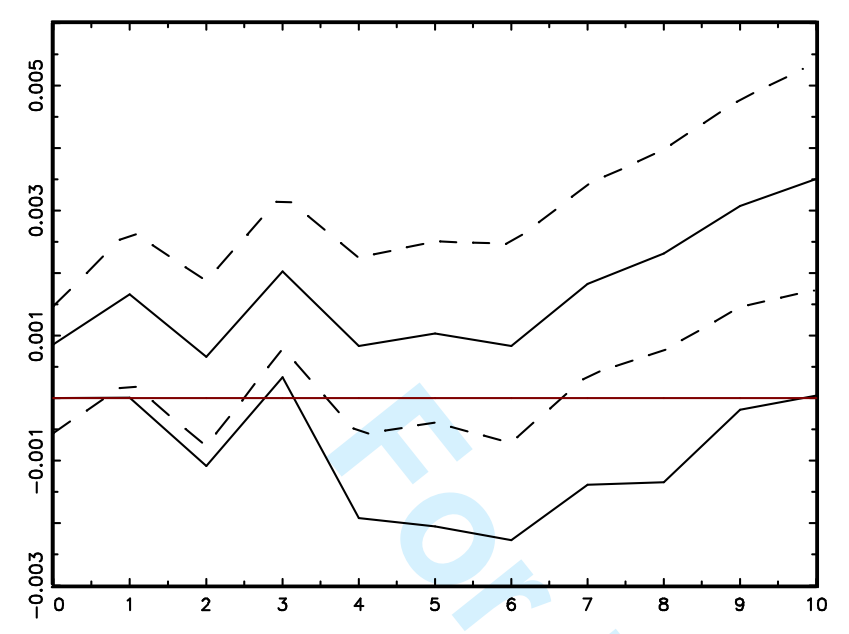

Note: Dotted lines show bootstrapped confidence intervals; lower line shows impulse responses with wealth channel turned off.

\section{FIGURE 3}

Actual and fitted consumption growth with and without positive wealth dynamics
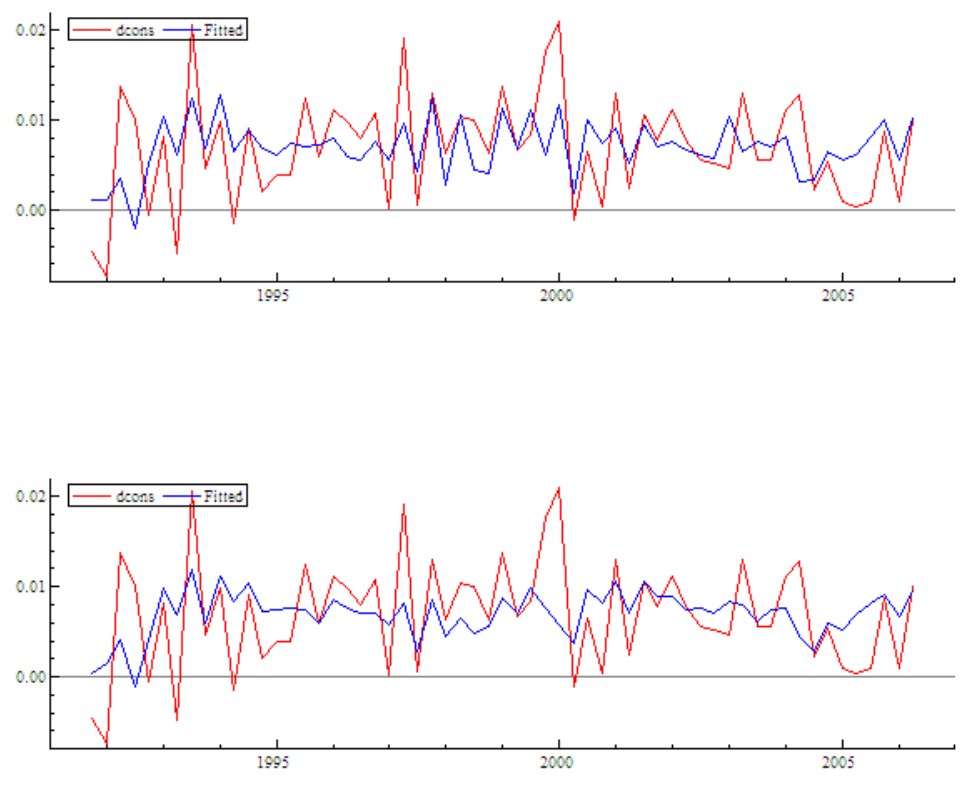

Editorial Office, Dept of Economics, Warwick University, Coventry CV4 7AL, UK 


\section{APPENDIX}

Figure A1: Impulse responses for $\operatorname{VAR}(5)$ using short term interest rate.

\section{SVAR Impulse Responses}
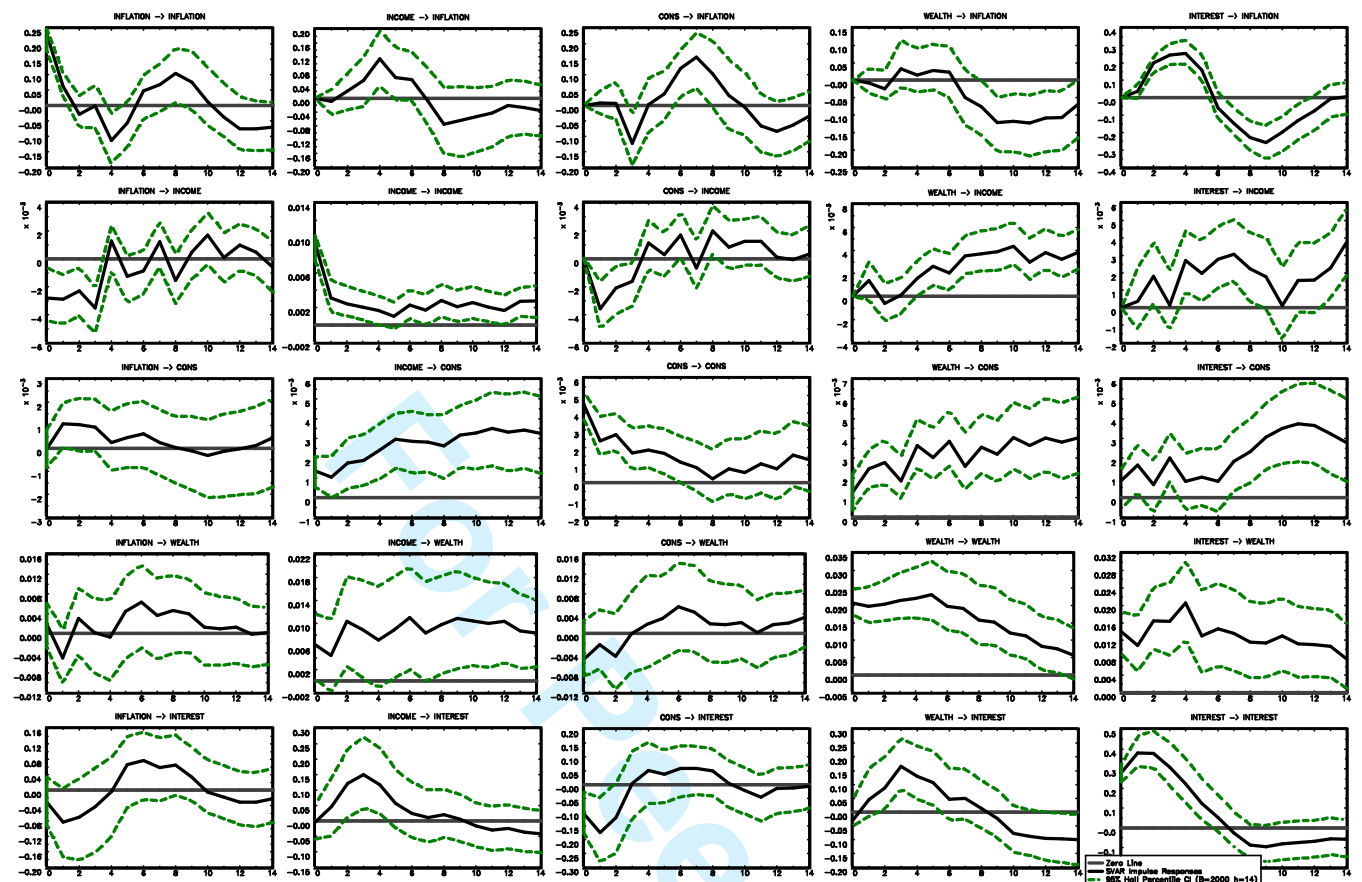

Rows show the response of each variable to shocks.

Figure A2: Impulse responses for VAR(5) using long term interest rate.

\section{SVAR Impulse Responses}
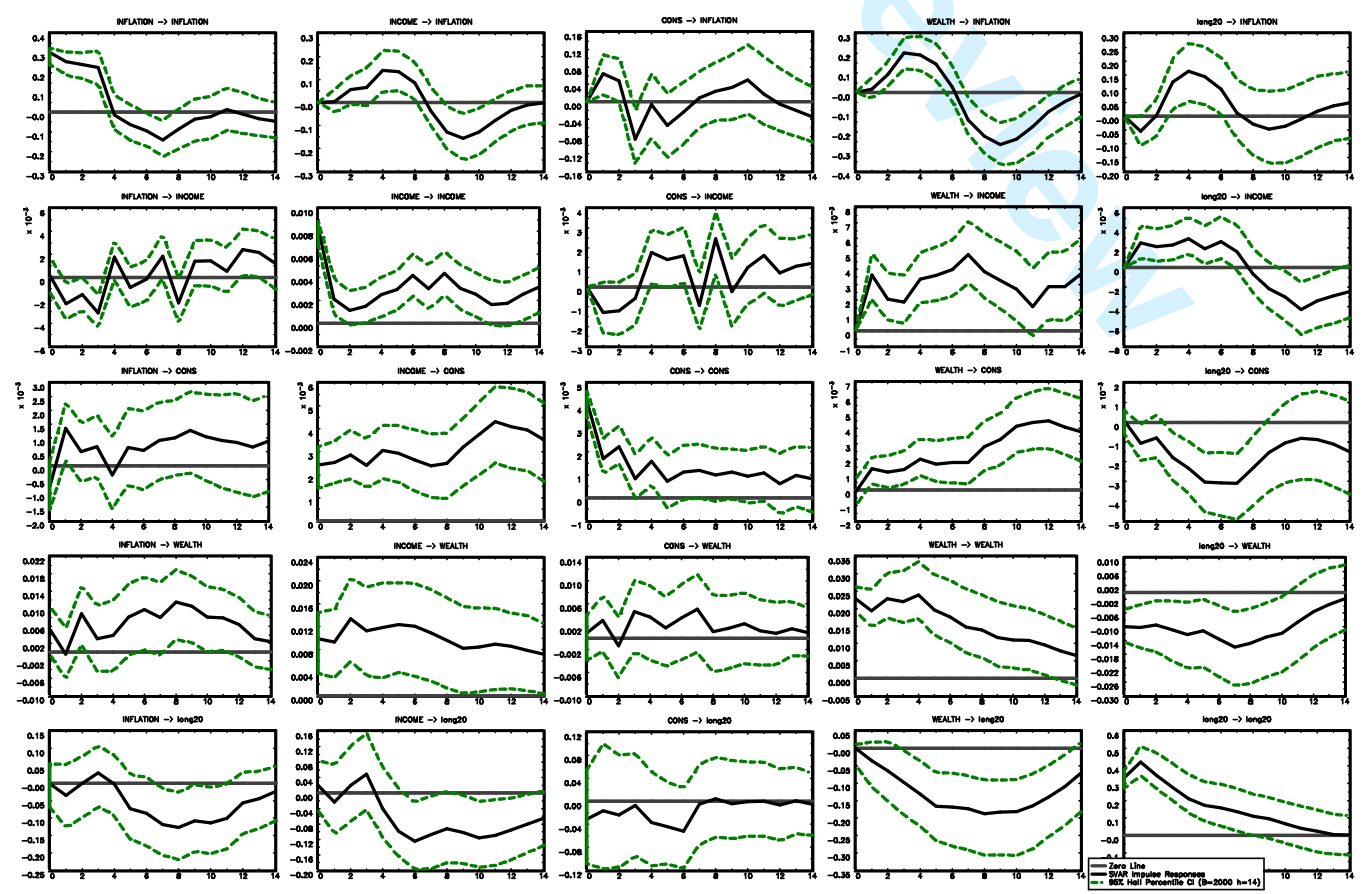